\title{
Speciation of arsenic compounds by ion-exchange HPLC-ICP-MS with different nebulizers
}

\author{
Kirsten Falk and Hendrik Emons* \\ Research Centre Juelich, Institute of Applied Physical Chemistry, D-52425 Juelich, Germany. \\ E-mail: h.emons@fz-juelich.de
}

Received 7th February 2000, Accepted 27th March 2000
Published on the Web 4th May 2000

For the purpose of environmental biomonitoring analytical procedures for the sensitive and efficient speciation of the arsenic species As(III), As(v), monomethylarsonic acid (MMA), dimethylarsinic acid (DMA),

trimethylarsine oxide (TMAO), tetramethylarsonium ion (Tetra), arsenobetaine and arsenocholine have been optimized. The influence of different nebulizers, in particular cross flow and hydraulic high pressure, on the analytical performance and quality parameters such as limit of detection and reproducibility was investigated. LODs in the range of a few pg or even below were achieved. The HPLC-ICP-MS procedures were validated by using reference materials.

\section{Introduction}

Arsenic is a widely distributed element in environmental systems and occurs in a large number of various species which differ not only in their physicochemical behaviour but also in toxicity, bioavailibility and biotransformation. In order to distinguish between the single species high performance liquid chromatography (HPLC) is a frequently used method for the separation, focused on the inorganic ions and the organic compounds monomethylarsonic acid (MMA), dimethylarsinic acid (DMA), arsenobetaine (AB), arsenocholine (AC), tetramethylarsonium ion (Tetra) and trimethylarsine oxide (TMAO). Applications of ion-exchange ${ }^{1-6}$ and ion-pairing reversed-phase chromatography ${ }^{2,7,8}$ have been reported, in which the latter is described to be more susceptible to matrix interferences. ${ }^{9,10}$

In contrast to urine samples where AB, DMA, MMA and the inorganic ions are the most frequently occurring arsenic compounds ${ }^{8,11-13}$ the species pattern in environmental samples is much more complex. The more information is obtained about the diversity of arsenic species in environmental samples the better the separation is supposed to be. With some exceptions using tandem MS spectrometry ${ }^{14,15}$ the identification of the arsenic compounds is mostly performed by comparing the retention times of standards with those of the peaks in the investigated samples. Therefore, a poor resolution can induce that unknown species with a slightly different retention time to be easily covered by other species. Also, compounds which elute with no retention can merge with other unknown species which elute with the dead volume as well. So it is necessary to get a good baseline separation of all species in an acceptable time. To our knowledge there is no method described in the literature where all eight arsenic species are baseline separated and no species elutes with the void volume in one chromatographic run. Therefore, the development of an ideal separation method of the eight arsenic species is still a major challenge.

The combination of HPLC with inductively coupled plasma mass spectrometry (ICP-MS) for detection is a powerful coupling technique for arsenic speciation..$^{10,13,16-21}$ The commonly used interfaces for arsenic speciation by using HPLC with ICP-MS detection are cross flow and the Meinhard-type nebulizer. Recently, B'Hymer et $a l^{22}$ have reported a comparison of the oscillating capillary nebulizer, concentric nebulizer and Meinhard-type high-efficiency nebulizer with different spray chambers. However, the total arsenic concentrations in environmental samples are in the lower $\mathrm{n} \mathrm{g}^{-1}$ level. Considering the dilution of the sample during the extraction and the separation on the column into the single species, very low concentrations of arsenic have to be determined. Although the sensitivity of ICP-MS is very good, the detection power obtained by these nebulizers is not sufficient because of their moderate nebulization and transport efficiency. Only a few papers on arsenic speciation have reported concerning improvement of the sensitivity by applying more efficient nebulizers like the ultrasonic nebulizer (USN) ${ }^{23}$ or the hydraulic high pressure nebulizer (HHPN). ${ }^{24}$

The purpose of the present work was to develop a powerful separation and detection method that allows the investigation of biological samples as part of systematic environmental monitoring. Therefore, this paper discusses the separation of eight arsenic compounds by anion-exchange and cationexchange chromatography coupled to ICP-MS, which was equipped with either a cross flow nebulizer, USN or HHPN. A systematic comparison of the different nebulizers on the chromatographic separation and on the behaviour of the arsenic species was performed.

\section{Experimental}

\section{Instrumentation}

The chromatographic system consisted of a Merck L-6220 Intelligent Pump (PEEK model; Merck, Darmstadt, Germany), a Rheodyne Model 9125 six-port injection valve fitted with a $20 \mu \mathrm{l}$ sample loop and a Mistral column thermostat (Spark Holland Instruments, Emmen, Netherlands). Two anion-exchange columns have been used: a PRP-X100 $(250 \times 4.1 \mathrm{~mm}$ id; Hamilton, Reno, USA) and an Ion-120 $(125 \times 4.6 \mathrm{~mm}$ id; Interaction Chromatography, San Jose, CA, USA). Both are based on polystyrene-divinylbenzene resins and consequently these columns are stable in a $\mathrm{pH}$ range from 1 to 13. Cation-exchange chromatography was performed on a Nucleosil 5SA $(250 \times 4.0 \mathrm{~mm}$ id; Machery-Nagel, Germany). All columns were used with the appropriate guard columns.

Different nebulizer systems were connected to the outlet of the HPLC. A cross flow nebulizer provided with a GemTip nozzle and a Scott-type spray chamber, a USN U-6000 AT ${ }^{+}$ (Cetac Technologies Inc., Omaha, Nebraska, USA) and a HHPN, which was constructed ourselves in cooperation with 
the Institute of Spectroscopy and Spectrochemistry (Dortmund, Germany). Using USN and HHPN the aerosol was dried by desolvation (heating to $100^{\circ} \mathrm{C}$, cooling to $0^{\circ} \mathrm{C}$ ). Therefore, the spray chamber of the HHPN was connected to the desolvation unit of an USN-5000 AT (Cetac Technologies Inc.).

The detection was performed with a Perkin Elmer Elan 5000 ICP-MS (Perkin Elmer Sciex, Thornhill, Ontario, Canada). The instrument was first optimized off-line for arsenic with an aqueous As(v) standard each time. The instrumental parameters for the ICP-MS coupled to HPLC are given in Table 1. The ion intensity at $m / z 77$ was monitored if an interference of ${ }^{40} \mathrm{Ar}{ }^{35} \mathrm{Cl}$ at $\mathrm{m} / \mathrm{z} 75$ was suspected. However, the interference was not observed in any instance.

\section{Reagents and standards}

For the preparation of reagents and standards Milli-Q (Millipore, Milford, MA, USA) water of $18.2 \mathrm{M} \Omega \mathrm{cm}$ was used. Except for $\mathrm{NH}_{3}$.aq and $\mathrm{NH}_{4} \mathrm{H}_{2} \mathrm{PO}_{4}$, both Suprapure quality, all chemicals for preparing the mobile phases were of pro analysi quality.

A commercially available arsenate solution $\left(1000 \mathrm{mg} \mathrm{l}^{-1}\right.$, $\mathrm{As}_{2} \mathrm{O}_{5}$ in $\mathrm{H}_{2} \mathrm{O}$ ) (Titrisol, Merck) was used. The $1000 \mathrm{ppm}$ As(III) standard was prepared by dissolution of $0.264 \mathrm{~g}$ arsenic trioxide (Aldrich, Milwaukee, WI, USA) in $200 \mathrm{ml} 0.2 \% \mathrm{NaOH}$ and used for about 2 months. Dimethylarsinic acid $(0.286 \mathrm{~g})$ (Fluka, Buchs, Switzerland) was dissolved in $100 \mathrm{ml}$ water to give a $1000 \mathrm{mg}^{-1}$ solution. Stock standard solutions (1000 $\mathrm{mg}^{-1} \mathrm{As}$ ) of $\mathrm{AB}, \mathrm{AC}$, Tetra, TMAO and MMA were

Table 1 Operating conditions for ICP-MS

\begin{tabular}{|c|c|}
\hline ICP-MS spectrometer & Perkin Elmer Elan 5000 \\
\hline Rf power & $1300 \mathrm{~W}$ \\
\hline Plasma gas & $15.0 \mathrm{ml} \mathrm{min}^{-1}$ \\
\hline Auxiliary gas & $0.81 \mathrm{ml} \mathrm{min}^{-1}$ \\
\hline Nebulizer gas $^{a}$ & $1.02 \mathrm{ml} \mathrm{min}^{-1}$ \\
\hline Cones & $\mathrm{Ni}$ and $\mathrm{Pt}$ \\
\hline Dwell time & $1100 \mathrm{~ms}$ \\
\hline Sweeps/reading & 1 \\
\hline Reading/replicate & 1 \\
\hline Analytical mass & $\mathrm{m} / \mathrm{z} 75$ and $\mathrm{m} / \mathrm{z} 77$ \\
\hline
\end{tabular}

kindly donated by W. Goessler (Institute for Analytical Chemistry, Karl-Franzens-University Graz, Austria).

The concentrations of the standards were checked by determination of the total arsenic by ICP-MS after acid digestion. All solutions were stored refrigerated and in the dark to prevent decomposition or oxidation. The final standard mixtures were prepared daily from a $20 \mathrm{ppm}$ standard solution except for As(III) which was prepared from a $1000 \mathrm{ppm}$ solution each time.

Certified reference materials used in the present study were DORM-2 (Dogfish Muscle) from the National Research Council of Canada (Ottawa, Canada) and CRM 627 (Tuna Fish) from BCR (IRMM Geel, Belgium).

\section{Chromatographic conditions}

The chromatographic conditions are presented in Table 2. The mobile phases were prepared by dissolving or dilution of the appropriate amount of $\mathrm{NH}_{4} \mathrm{HCO}_{3}, \mathrm{NH}_{4} \mathrm{H}_{2} \mathrm{PO}_{4}$ or pyridine in Milli-Q water, adding 2\% (v/v) methanol for increasing the sensitivity of the ICP-MS signals and afterwards adjusting the $\mathrm{pH}$ according to the values mentioned in Table 2. All mobile phases were deaerated with helium before use.

For quantification of the arsenic species standard addition was used. Calculation was performed with the Perkin Elmer (Ueberlingen, Germany) software Chromafile MS plus 1.0. The quantification of the chromatographic peaks was based on the peak area.

\section{Extraction procedure}

The certified reference materials were extracted by a procedure slightly modified in comparison to a method of Goessler et $_{\text {al. }}{ }^{24}$ Approximately $0.2 \mathrm{~g}$ of the freeze-dried sample was weighed into a $16 \mathrm{ml}$ polyethylene centrifuge tube and $10 \mathrm{ml}$ of methanol-water $(9+1 \mathrm{v} / \mathrm{v})$ were added. The tubes were shaken overnight. Afterwards the extracts were centrifuged at $17000 \mathrm{rpm}$ for $15 \mathrm{~min}$ and the clear supernatants were transfered into round bottomed flasks. The extraction residues were washed three times with methanol-water $(9+1 \mathrm{v} / \mathrm{v})$. The extracts were combined and the methanol was evaporated on a rotary evaporator at temperatures not above $35^{\circ} \mathrm{C}$. Each sample was filled up to $10 \mathrm{ml}$ with water. Before injection the sample was filtered through a $0.22 \mu \mathrm{m}$ cellulose filter (Sartorius,

Table 2 Operating conditions for the chromatographic system

\begin{tabular}{|c|c|c|}
\hline Column & & Parameters \\
\hline Hamilton PRP-X100 & $\begin{array}{l}\text { Mobile phase A: } \\
\text { Mobile phase B: } \\
\text { Gradient program: }\end{array}$ & $\begin{array}{l}0.25 \mathrm{mmol} \mathrm{l}^{-1} \mathrm{NH}_{4} \mathrm{H}_{2} \mathrm{PO}_{4} ; 2 \%(\mathrm{v} / \mathrm{v}) \mathrm{MeOH} ; \mathrm{pH} 9.0^{a} \\
20 \mathrm{mmol} 1^{-1} \mathrm{NH}_{4} \mathrm{H}_{2} \mathrm{PO}_{4} ; 2 \%(\mathrm{v} / \mathrm{v}) \mathrm{MeOH} ; \mathrm{pH} 8.8^{a} \\
100 \% \text { A for } 5 \mathrm{~min} \text {, decreasing to } 100 \% \mathrm{~B} \text { in } 0.1 \mathrm{~min} \text { and maintaining for } 10 \mathrm{~min} \text {. Regeneration } \\
\text { for } 10 \text { min with } 100 \% \mathrm{~A}\end{array}$ \\
\hline Ion-120 & $\begin{array}{l}\text { Mobile phase A: } \\
\text { Mobile phase B: } \\
\text { Gradient program: }\end{array}$ & $\begin{array}{l}5 \mathrm{mmol} l^{-1} \mathrm{NH}_{4} \mathrm{HCO}_{3} ; 2 \%(\mathrm{v} / \mathrm{v}) \mathrm{MeOH} ; \mathrm{pH} 10.3^{a} \\
50 \mathrm{mmol} 1^{-1} \mathrm{NH}_{4} \mathrm{HCO}_{3} ; 2 \%(\mathrm{v} / \mathrm{v}) \mathrm{MeOH} ; \mathrm{pH} 10.3^{a} \\
100 \% \text { A for } 1 \mathrm{~min} \text {, decreasing to } 100 \% \mathrm{~B} \text { in } 3 \mathrm{~min} \text { and maintaining for } 6 \mathrm{~min} \text {. Regeneration for } \\
10 \text { min with } 100 \% \text { A }\end{array}$ \\
\hline & Isocratic mode: & $30 \mathrm{mmol} \mathrm{l}^{-1} \mathrm{NH}_{4} \mathrm{HCO}_{3}, 2 \%$ (v/v) $\mathrm{MeOH} ; \mathrm{pH} 10.0^{a}$ \\
\hline
\end{tabular}

Cation-exchange chromatography-

Column

Nucleosil 5SA

Isocratic mode:

Other parameters-

Temperature

Injection volume

Flow rate

$25^{\circ} \mathrm{C}$

$20 \mu \mathrm{l}$

$1 \mathrm{ml} \mathrm{min}^{-1}$

${ }^{a} \mathrm{pH}$ adjusted with $\mathrm{NH}_{3}$.aq.

Parameters

$30 \mathrm{mmol}^{-1}$ pyridine; $2 \%$ (v/v) $\mathrm{MeOH}$; $\mathrm{pH} 3.0$ (adjusted with $\mathrm{HCOOH}$ ) 


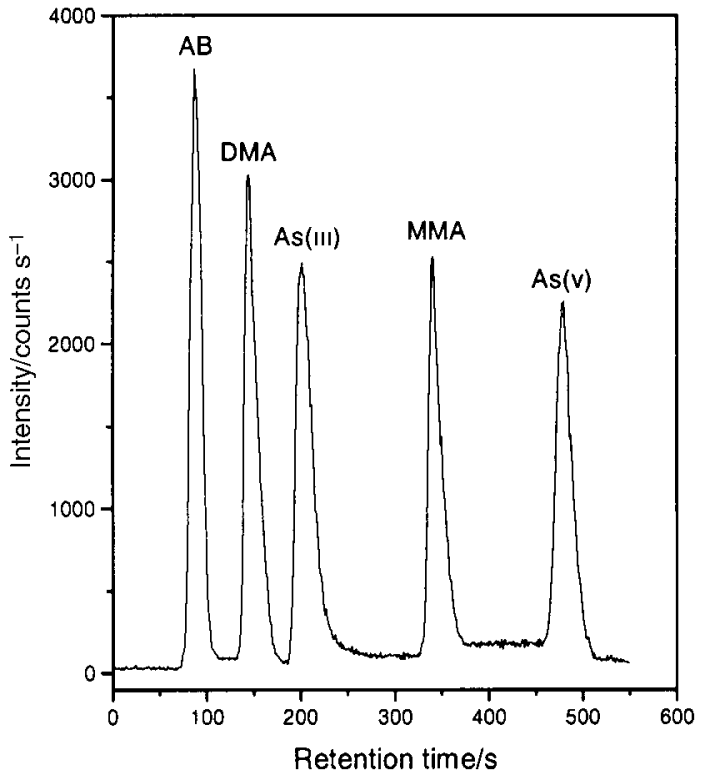

Fig. 1 HPLC-ICP-MS chromatogram for the separation of As(III), As(v), MMA, DMA and AB (in distilled water, each species $50 \mu \mathrm{g}$ As $1^{-1}$ ) using cross flow nebulizer, Ion-120 anion-exchange column and $\mathrm{NH}_{4} \mathrm{HCO}_{3}$ gradient (for details of conditions see Table 2).

Goettingen, Germany) and diluted with water to an appropriate concentration.

\section{Results and discussion}

The arsenic species As(III), As(v), DMA, MMA, AB, AC, Tetra and TMAO occur as neutral, positively or negatively charged compounds depending on the $\mathrm{pH}$ so that ion exchange chromatography appears to be a suitable method for separation. To obtain a good resolution of these eight arsenic species in an acceptable time concerning the facts mentioned above anion-exchange and cation-exchange chromatography was used.

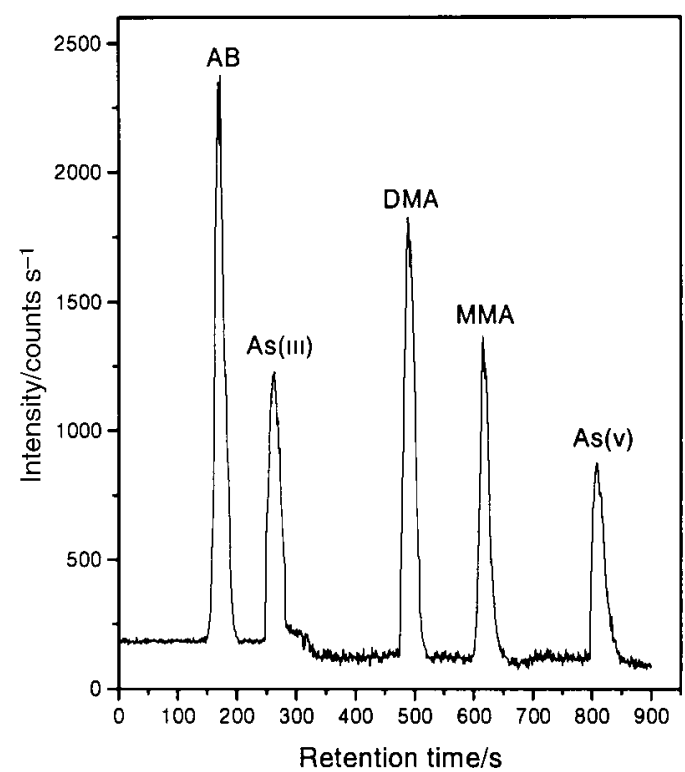

Fig. 2 HPLC-ICP-MS chromatogram for the separation of As(III), As(v), MMA, DMA and AB (in distilled water, each species $50 \mu \mathrm{g}$ As $1^{-1}$ ) using cross flow nebulizer, Hamilton PRP-X100 anionexchange column and $\mathrm{NH}_{4} \mathrm{H}_{2} \mathrm{PO}_{4}$ gradient (for details of conditions see Table 2).
Separation of arsenic compounds by anion-exchange chromatography

The four arsenic species As(III), As(v), DMA and MMA were separated using anion-exchange chromatography. For the retention of arsenite with a $\mathrm{p} K_{\mathrm{a}}$ value of 9.2 it is necessary to work in a basic environment otherwise As(III) will elute with the void volume. Because silica-based columns can only be applied in a $\mathrm{pH}$ range up to 7 polystyrene-divinylbenzene-based anionexchange columns were used.

For optimization of the chromatographic parameters the influence of $\mathrm{pH}$, composition and concentration of the mobile phase and temperature was studied for two different anionexchange columns. Cross flow nebulizer gradient programs were found to provide the best separation where all species were baseline resolved and none of the anionic compounds eluted with the void volume. Therefore, a gradient programme with $\mathrm{NH}_{4} \mathrm{H}_{2} \mathrm{PO}_{4}$ buffer as mobile phase using a PRP-X100 column and a $\mathrm{NH}_{4} \mathrm{HCO}_{3}$ buffer for the Ion-120 was used. The detailed conditions are shown in Table 2. Corresponding chromatograms are presented in Figs. 1 and 2. The separation behaviour was similar on both columns: the arsenic species $\mathrm{AB}$, $\mathrm{AC}$, Tetra and TMAO which are cations at basic $\mathrm{pH}$ eluted with the void volume. MMA and As(v) appeared in the same order. However, As(III) and DMA showed reversed retention behaviour.

On the Ion-120 As(III) eluted later than DMA. That is surprising, because at the $\mathrm{pH}$ of 10.3 both species have an apparent charge of -1 and it would be more likely that the larger hydrophobic interactions of DMA to the stationary phase cause a longer retention time. Decreasing the $\mathrm{pH}$ resulted in an approach of both peaks and at $\mathrm{pH}$ between 9.5 and 9 they merge completely.

On the column RPR-X100 the pH used was lower. A higher $\mathrm{pH}$ would cause an overlapping of As(III) and DMA so that the best separation was achieved at $\mathrm{pH} 8.8$.

After optimization of the separation using the cross flow nebulizer the method was applied to a USN for increasing the detection power. By measuring the baseline during the gradient program an increase of the baseline on both columns was observed when mobile phase $B$ with the higher buffer concentration was started. Also a peak at the same retention time of $\mathrm{As}(\mathrm{v})$ arose although no injection was carried out (Fig. 3). The effects varied depending on the regeneration time: the peak increased seriously if the time between the two injections was longer, especially after conditioning of the column. It was supposed that an impurity of arsenic may be responsible for this phenomenon. The total arsenic content in

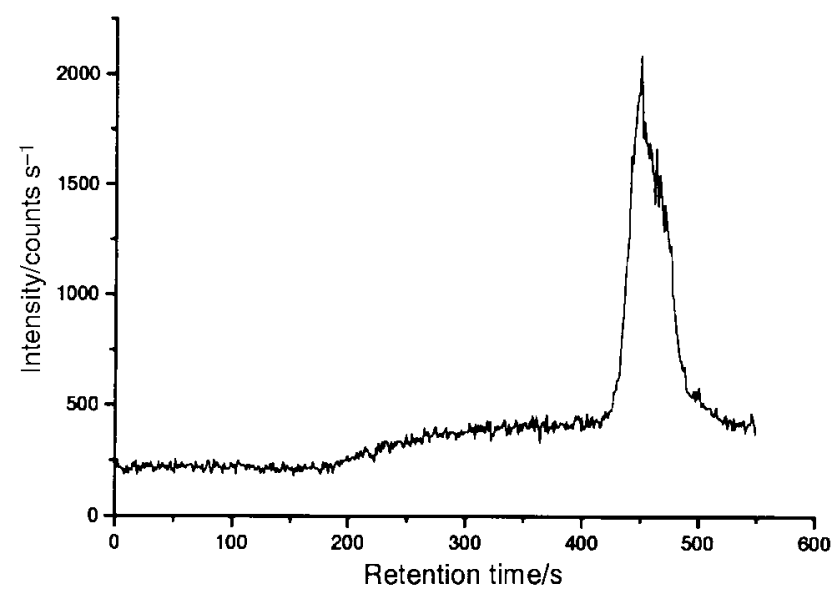

Fig. 3 Baseline running the $\mathrm{NH}_{4} \mathrm{HCO}_{3}$ gradient programme on an ION-120 anion-exchange column using USN for nebulisation without any injection. 


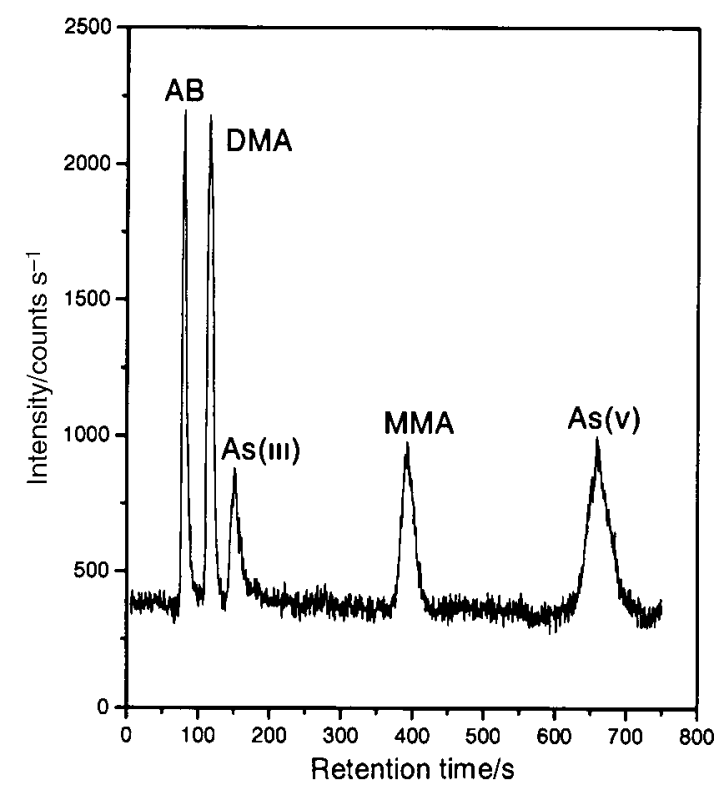

Fig. 4 HPLC-ICP-MS chromatogram for the separation of As(III), As(v), MMA, DMA and AB (in distilled water, each species $2 \mu \mathrm{g}$ $\mathrm{As}^{-1}$ ) using HHPN and an ION-120 anion-exchange column (mobile

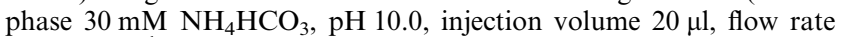
$1.0 \mathrm{ml} \mathrm{min}{ }^{-1}, 25^{\circ} \mathrm{C}$ ).

the $\mathrm{NH}_{4} \mathrm{HCO}_{3}$ was determined and resulted in a concentration of $2.5 \mathrm{ng} \mathrm{g}^{-1}$ As. It is very likely that this arsenic impurity in the form of $\mathrm{As}(\mathrm{v})$ was accumulated on the column during the regeneration and conditioning steps, respectively. In both steps the lower buffer concentration of the gradient programme was used where no elution of $\mathrm{As}(\mathrm{v})$ takes place. Running the gradient programme the accumulated arsenic could be mobilized when mobile phase $\mathrm{B}$ with the higher buffer concentration was started and a peak appeared after almost the same retention time as when $\mathrm{As}(\mathrm{v})$ was injected. Therefore, different $\mathrm{NH}_{4} \mathrm{HCO}_{3}$ salts were tested but all of them showed similar behaviour. Also experiments with the HHPN produced the same results. There was no further testing performed with other $\mathrm{NH}_{4} \mathrm{H}_{2} \mathrm{PO}_{4}$ salts because the use of this mobile phase seems to cause damage to the sampler cone, possibly because of the relatively high efficiency of the HHPN $(15 \%)$ compared to the cross flow nebulizer and hence to a higher transfer of phosphate into the plasma.

The effect of an arsenic impurity in the mobile phase during a gradient programme was not observed by using a cross flow nebulizer, probably because of the lower sensitivity of this nebulizer. But this effect was also observed on another column with another gradient programme and a Meinhard-type nebulizer.

Because mobile phases slightly contaminated with arsenic did not allow the running of a gradient programme with use of the more efficient nebulizers USN and HHPN, further investigations were performed with an isocratic mode to separate the anionic arsenic species.

Based on an approach proposed by Hansen et al. ${ }^{18}$ the separation of the four anionic arsenic species in an isocratic mode on the Ion-120 anion-exchange column was optimized for the system used in this study. Compared to the method of Hansen it was found that a lower concentration of the $\mathrm{NH}_{4} \mathrm{HCO}_{3}$ buffer and a lower temperature was necessary to obtain a good separation of As(v), As(III), MMA and DMA. A chromatogram using the HHPN is presented in Fig. 4. Similar to the separation by the gradient mode mentioned above, AB, AC, Tetra and TMAO eluted with the void volume.

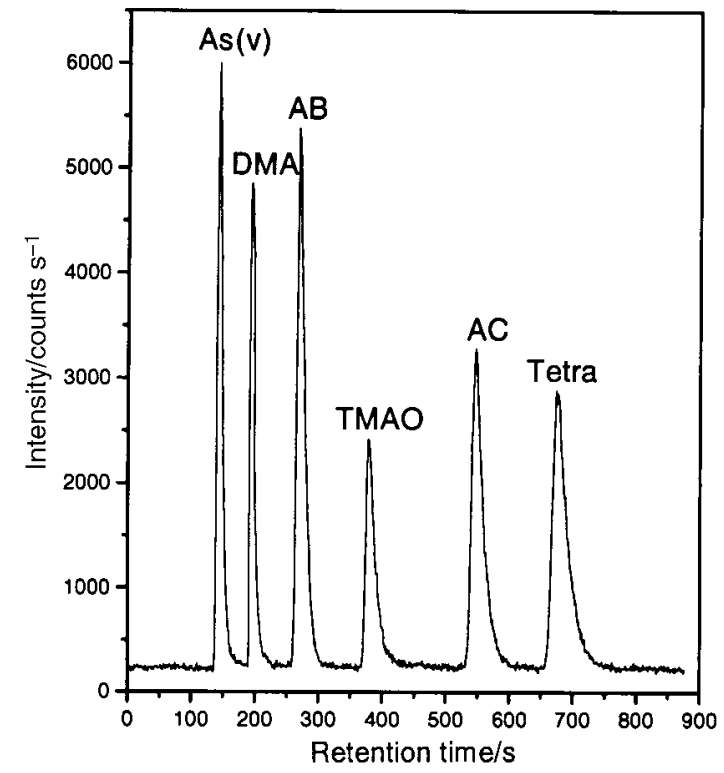

Fig. 5 HPLC-ICP-MS chromatogram for the separation of DMA, As(v) AB, AC, Tetra and TMAO (in distilled water, each species $2 \mu \mathrm{g}$ $\mathrm{As}^{-1}$ ) using HHPN, Nucleosil 5SA cation-exchange column (mobile phase $30 \mathrm{mM}$ pyridine, $\mathrm{pH} 3.0$, injection volume $20 \mu \mathrm{l}$, flow rate $1.0 \mathrm{ml} \mathrm{min}{ }^{-1}, 25^{\circ} \mathrm{C}$ )

\section{Separation of arsenic compounds by cation-exchange} chromatography

For the separation of AB, AC, Tetra and TMAO a Nucleosil 5SA cation-exchange column was used. Approaches using pyridine as mobile phase under isocratic conditions have already been described in the literature. ${ }^{18,19}$ First the optimization of $\mathrm{pH}$, temperature and concentration of pyridine was performed with a cross flow nebulizer. The following transfer to USN and HHPN, respectively, was achieved without any problem. A chromatogram is presented in Fig. 5 using HHPN for nebulization. It is shown that As(v), DMA, $\mathrm{AB}, \mathrm{TMAO}, \mathrm{AC}$ and Tetra are very well baseline separated. The retention of DMA on a cation-exchange column may be an effect of the formation of $\left(\mathrm{CH}_{3}\right)_{2} \mathrm{As}^{+}(\mathrm{OH}) \cdot{ }^{18}$ The species MMA and As(III) elute between As(v) and DMA. If a real sample contains all four anionic species in similar amounts the separation will be successful for qualitative analysis but for quantitative analysis it will be not sufficient. As(v) elutes with the void volume and therefore it is likely that it will appear together with unknown negatively or uncharged arsenic species. Therefore, As(v) is better quantified by anion-exchange chromatography.

\section{Influence of nebulizer and chromatographic parameters on the} signal intensity

Measurements of the eight arsenic species in $\mathrm{HNO}_{3}$ solutions by ICP-MS with the cross flow nebulizer without any chromatographic system provided the same intensity for each compound. However, the HPLC-ICP-MS chromatograms presented in Figs. 4 and 5 exhibit that the signal intensities of the eight arsenic species are different. Especially As(III) in the anion-exchange chromatogram and DMA and TMAO in the cation-exchange chromatogram show significant lower intensities compared to the other species. The signal depression might be an effect of the column and/or of the nebulizer system. Therefore, investigations were performed to study the signal intensities of the arsenic species with and without the column in combination with two different kinds of nebulizers. The species were separated on the appropriate ion-exchange column which was connected to HHPN and cross flow nebulizer, respectively. Thereafter, each species was injected separately without the 
Table 3 Influence of nebulizer and chromatographic parameters on the signal intensity (peak area) of the arsenic species (values are the relative intensities related to $\mathrm{As}(\mathrm{v})$ which was normalized to 1 for each run)

\begin{tabular}{|c|c|c|c|c|c|c|c|c|c|c|}
\hline Mobile phase & Nebulizer & Column & $\operatorname{As}(v)$ & DMA & $\mathrm{AB}$ & TMAO & $\mathrm{AC}$ & Tetra & As(III) & MMA \\
\hline \multirow[t]{4}{*}{ Pyridine } & \multirow[t]{2}{*}{ HHPN } & Nucleosil & 1 & 0.80 & 1.05 & 0.67 & 0.96 & 1.00 & & \\
\hline & & No & 1 & 0.81 & 1.03 & 0.64 & 0.99 & 0.98 & & \\
\hline & \multirow[t]{2}{*}{ Cross flow } & Nucleosil & 1 & 1.01 & 1.05 & 1.00 & 0.99 & 1.08 & & \\
\hline & & No & 1 & 0.99 & 1.02 & 1.02 & 0.99 & 1.05 & & \\
\hline \multirow{4}{*}{$\mathrm{NH}_{4} \mathrm{HCO}_{3}$} & \multirow[t]{2}{*}{ HHPN } & ION-120 & 1 & 0.95 & 0.94 & & & & 0.33 & 0.87 \\
\hline & & No & 1 & 0.95 & 0.96 & & & & 0.66 & 0.87 \\
\hline & \multirow[t]{2}{*}{ Cross flow } & ION-120 & 1 & 0.92 & 0.96 & & & & 0.68 & 0.88 \\
\hline & & No & 1 & 0.98 & 1.05 & & & & 0.99 & 0.91 \\
\hline
\end{tabular}

column, just running the same mobile phase which was used for the relevant separation. The results are summarized in Table 3. The values represent relative intensities related to the intensity of $\operatorname{As}(\mathrm{v})$ which was normalized to 1 for each run. For this experiment the total arsenic concentrations of the standards were checked by ICP-MS after acid digestion.

Table 3 shows that the intensities obtained for DMA and TMAO using the separation with pyridine as mobile phase on the cation-exchange column and HHPN for nebulization (Fig. 4) were just 80 and $67 \%$, respectively, compared to the As(v) signal. But in the case of the cross flow nebulizer the intensities of the six investigated compounds were almost equal $(99-108 \%)$. On the other hand the relative intensities for DMA and TMAO with and without the Nucleosil column are similar in each case (DMA: 0.80 and 0.81; TMAO: 0.67 and 0.64). The same behaviour is observed if a cross flow nebulizer is used (DMA: 1.01 and 0.99; TMAO: 1.00 and 1.02). This indicates that the lower sensitivity of DMA and TMAO is not an effect of the column but of the nebulizer. A loss of these species in the desolvation step of the HHPN would be a possible explanation.

To investigate the influence of the desolvation the intensities of the species were determined with regard to dependence on the heating temperature in this step (Fig. 6). A temperature increase enhances the vaporization of eluent in the aerosol which will cause a higher sensitivity. As expected an increase of the signal intensities at higher temperatures could be observed in the case of the species As(v), DMA, AB, AC and Tetra. However, TMAO showed a reverse behaviour: the intensity of this species decreased by about $40 \%$ after changing the temperature from $100{ }^{\circ} \mathrm{C}$ to $160^{\circ} \mathrm{C}$. The different behaviour of TMAO indicates that there is another effect during the desolvation of this particular species, which eventually causes the lower intensity of TMAO in the cation-exchange chromatogram.

Concerning the anion-exchange chromatography on the Ion120 (Fig. 4) As(III) exhibited a much lower signal intensity than

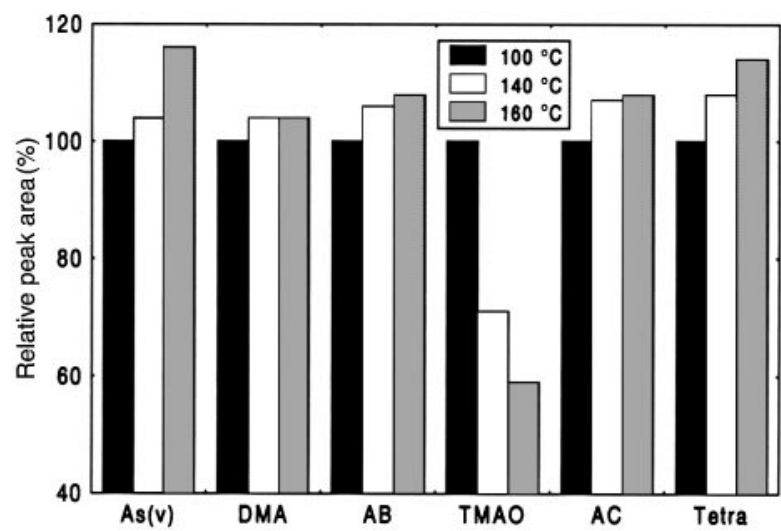

Fig. 6 Arsenic signal as peak area of As(v), DMA, AB, AC, Tetra and TMAO obtained as a function of the heating temperature in the desolvation unit of the HHPN (intensity at $100{ }^{\circ} \mathrm{C}$ was set to $100 \%$ ). Mean value (three repetitions, RSD 1-4\%), separation conditions as for Fig. 5.

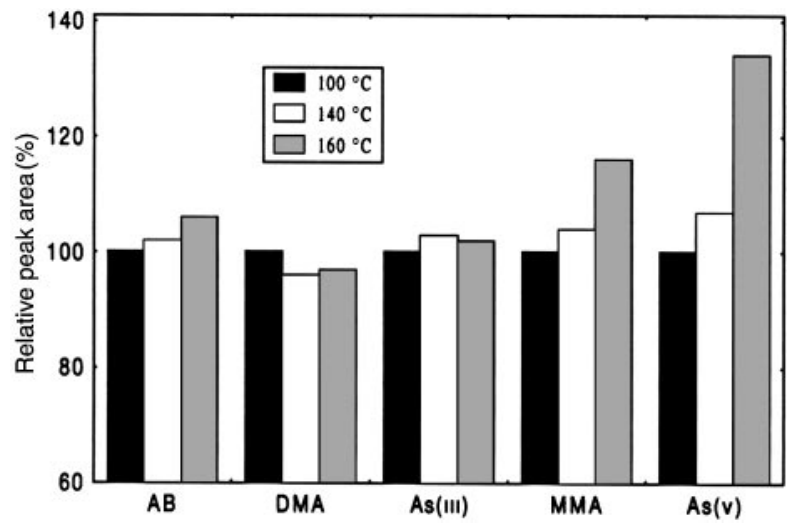

Fig. 7 Arsenic signal as peak area of DMA, MMA, AB, As(III) and As(v) obtained as a function of the heating temperature in the desolvation unit of the HHPN (intensity at $100^{\circ} \mathrm{C}$ was set to $100 \%$ ). Mean value (three repetitions, RSD 1-4\%), separation conditions as for Fig. 4.

the other species (33\% in comparison to the $\mathrm{As}(\mathrm{v})$ signal). Table 3 shows an increase of the intensity if the column was removed and also if the HHPN was replaced by a cross flow nebulizer. Therefore, the lower intensity of As(III) seems to be an effect of both the column and the nebulizer.

Corresponding investigations regarding the dependence of the intensity on the heating temperature in the desolvation step were also performed for the species separated by anionexchange chromatography (Fig. 7). The expected increase of the intensity with higher temperature is obtained in the case of As(v), MMA and AB, with the strongest effect on As(v). The intensities of DMA and As(III) are almost similar at each temperature.

These experiments demonstrated that the eight arsenic species show a different behaviour in the desolvation step using HHPN. Therefore, it can be assumed that the HHPN nebulizer system is a reason for the different intensities of the species in the HPLC-ICP-MS chromatograms. But in the case of As(III) other effects besides nebulization seem also to contribute to the lower intensity of this species.

\section{Detection limits and precision of the methods}

The detection limits were determined by using the calibration curve method $\left(c_{\mathrm{dl}}=4 s_{\mathrm{xc}} / m ; m=\right.$ slope of a calibration curve close to the detection limit, $s_{\mathrm{xc}}=$ standard deviation as a function of the deviations of the measurements of each concentration). $\dagger$ In comparison to the $3 \sigma$ method the

$\dagger S_{\mathrm{xc}}=\left[\frac{\sum_{i} \sum_{j}\left(x_{i, j}-\bar{x}_{i}\right)^{2}}{n-2}\right]^{1 / 2}$

where $i=$ Concentration $i, n=$ total number of measurements, $j=$ repetitive measurements at one concentration $i$. 
Table 4 Detection limits (pg As) and relative standard deviations (eight repetitions) obtained by using HPLC-ICP-MS with cross flow nebulizer and HHPN, respectively, and cation-exchange chromatography

\begin{tabular}{|c|c|c|c|c|}
\hline \multirow[b]{3}{*}{ Arsenic species } & \multicolumn{4}{|l|}{ Nebulizer } \\
\hline & \multicolumn{2}{|l|}{ Cross flow } & \multicolumn{2}{|l|}{ HHPN } \\
\hline & Detection limit/pg & RSD for $20 \mu \mathrm{g} \mathrm{l^{-1 }}(\%)$ & Detection limit/pg & RSD for $2 \mu \mathrm{gl}^{-1}(\%)$ \\
\hline $\operatorname{As}(v)$ & 11 & 2.0 & 0.68 & 1.3 \\
\hline DMA & - & 1.8 & - & 3.1 \\
\hline $\mathrm{AB}$ & 13 & 1.8 & 0.72 & 1.7 \\
\hline $\mathrm{AC}$ & 13 & 2.3 & 1.05 & 3.2 \\
\hline TMAO & 7 & 1.7 & 1.58 & 2.2 \\
\hline Tetra & 18 & 2.5 & 2.01 & 3.1 \\
\hline
\end{tabular}

Table 5 Detection limits (pg As) and relative standard deviations (eight repetitions) obtained by using HPLC-ICP-MS with cross flow nebulizer and HHPN, respectively, and anion-exchange chromatography

\begin{tabular}{|c|c|c|c|c|}
\hline \multirow[b]{3}{*}{ Arsenic species } & \multicolumn{4}{|l|}{ Nebulizer } \\
\hline & \multicolumn{2}{|l|}{ Cross flow } & \multicolumn{2}{|l|}{ HHPN } \\
\hline & Detection limit/pg & RSD for $20 \mu \mathrm{g} \mathrm{l}^{-1}(\%)$ & Detection limit/pg & RSD for $2 \mu \mathrm{g} \mathrm{l}^{-1}(\%)$ \\
\hline As (v) & 15 & 2.4 & 5.5 & 2.7 \\
\hline As (III) & 32 & 3.6 & 9.3 & 8.1 \\
\hline $\mathrm{AB}$ & 13 & 2.2 & 3.5 & 1.1 \\
\hline DMA & 11 & 2.0 & 6.0 & 2.2 \\
\hline MMA & 16 & 1.7 & 6.5 & 3.4 \\
\hline
\end{tabular}

calibration curve method considers not only the sensitivity but also the reproducibility of single species determinations. Tables 4 and 5 show the detection limits and reproducibilities for the cation-exchange and anion-exchange chromatography, respectively.

In the case of cation-exchange chromatography using HHPN as nebulizer the detection limits for As(v), AB, AC and Tetra are 10 to 20 times higher than using the cross flow nebulizer. However, the detection limits for TMAO improved by just a factor of four. This corresponds to the effect of TMAO using HHPN which has been discussed above. Surprisingly the reproducibility of TMAO determination with HHPN is comparable to the other compounds which resulted in the relatively low detection limit despite the lower intensity of this species in the chromatogram.

Regarding the determination of the anionic species the detection limits for using the cross flow nebulizer (Table 5) are in the same range as the cationic species in Table 4. However, the detection limits are higher for the anionic species than for the cationic species using HHPN. It is likely that the mobile phase $\mathrm{NH}_{4} \mathrm{HCO}_{3}$ used in the anion-exchange chromatography changed the condition of the plasma of the ICP-MS because of the higher salt concentration. This effect would be more pronounced with the HHPN because of its higher efficiency. Beside an influence on the plasma conditions the higher salt concentration could also influence the nebulization and desolvation.

\section{Arsenic speciation in certified reference materials}

For testing the accuracy of the methods in real samples two reference materials were investigated. Tuna fish from BCR was to our knowledge the first reference material which has been certified for arsenic species. For DORM-2 only the comparison to other published results can be used to check the method. The quantification of DMA was performed using both cation- and anion-exchange chromatography. The concentrations obtained with both methods were consistent so that the results were combined. $\mathrm{AB}$ and Tetra were determined by cation-exchange chromatography. In all cases HHPN was used as nebulizer

The concentrations found for $\mathrm{AB}\left(3.81 \pm 0.05 \mu \mathrm{g} \mathrm{g}^{-1} \mathrm{As}\right)$ and
Table 6 Concentrations of arsenic species $\left(\mu \mathrm{g} \mathrm{As}^{-1}\right)$ in the reference material DORM-2

\begin{tabular}{llll}
\hline \multirow{3}{*}{ Arsenic species } & \multicolumn{2}{l}{ Concentration } \\
\cline { 2 - 4 } & Ref. 14 & Ref. 25 & This work \\
\hline Arsenobetaine & $16.6 \pm 0.6$ & $16.0 \pm 0.7$ & $17.2 \pm 0.5$ \\
Dimethylarsinic acid & & $0.28 \pm 0.01$ & $0.42 \pm 0.02$ \\
Tetramethylarsonium ion & & $0.23 \pm 0.02$ & $0.26 \pm 0.01$ \\
\hline
\end{tabular}

DMA $\left(0.145 \pm 0.006 \mu \mathrm{g} \mathrm{g}^{-1}\right.$ As) are in very good agreement with the certified concentrations in the CRM 627 (AB $3.90 \pm 0.24 \mu \mathrm{g} \mathrm{g}^{-1}$ As, DMA: $\left.0.15 \pm 0.02 \mu \mathrm{g} \mathrm{g}^{-1} \mathrm{As}\right)$.

The concentration of $\mathrm{AB}$ in DORM-2 (Table 6) varies in a range of 16.0 to $17.2 \mu \mathrm{g} \mathrm{g}^{-1}$ As. Related to the total arsenic concentration of DORM-2 (18.01.1 $\mathrm{mg} \mathrm{g}^{-1}$ As) the percentage of $\mathrm{AB}$ is between 88 and $95 \%$. By considering the low concentration of DMA and Tetra the results are comparable, even if we found a DMA concentration which is by a factor of two higher than published by Goessler et al. ${ }^{25}$

\section{Conclusions}

The optimized analytical procedures offer sufficient detection power and reproducibility for the investigation of species patterns of As(III), As(v), MMA, DMA, TMAO, Tetra, AB and $\mathrm{AC}$ in bioindicators from different ecosystems. The anionexchange and cation-exchange chromatography is not suited for the analysis of arsenosugars which occur at low trophic levels in the marine environment. For that purpose other chromatographic approaches have to be used.

\section{References}

1 J. Gailer and K. Irgolic, J. Appl. Organomet. Chem., 1994, 8, 129.

2 P. Morin, M. B. Amran, S. Favier, R. Heimburger and M. Leroy, Fresenius' J. Anal. Chem., 1991, 339, 504.

3 S. Saverwyns, X. Zhang, F. Vanhaecke, R. Cornelis, L. Moens and R. Dams, J. Anal. At. Spectrom., 1997, 12, 1047.

4 M. A. López, M. M. Gómez, M. A. Palacios and C. Cámara, Fresenius' J. Anal. Chem., 1993, 346, 643. 
5 M. A. López-Gonzálvez, M. M. Gómez, C. Cámara and M. A. Palacios, J. Anal. At. Spectrom., 1994, 9, 291.

6 X. Zhang, R. Cornelis and J. D. K. L. Mees, Anal. Chim. Acta, 1996, 319, 177.

7 X. C. Le and M. Ma, J. Chromatogr. A, 1997, 764, 55.

8 E. Hakala and L. Pyy, J. Anal. At. Spectrom., 1992, 7, 191.

9 D. Beauchemin, K. W. M. Siu, J. W. McLaren and S. S. Berman, J. Anal. At. Spectrom., 1989, 4, 285.

10 C. Demesmay, M. Olle and M. Porthault, Fresenius' J. Anal. Chem., 1994, 348, 205.

11 M. Vather, Clin. Chem., 1994, 40, 679

12 R. Ritsema, L. Dukan, T. R. Navarro, W. van Lee, N. Oliveira, P. Wolfs and E. Lebret, Appl. Organometal Chem , 1998, 12, 591.

13 J. Lintschinger, P. Schramel, A. Hatalak-Rauscher, I. Wendler and B. Michalke, Fresenius' J. Anal. Chem., 1998, 362, 313.

14 J. J. Corr, J. Anal. At. Spectrom., 1997, 12, 537.

15 J. J. Corr and E. H. Larsen, J. Anal. At. Spectrom., 1996, 11, 1215.

16 S. Caroli, F. La Torre, F. Petrucci and N. Violante, Environ. Sci. Pollut. Res., 1994, 1, 205.
17 V. W.-M. Lai, W. R. Cullen, C. F. Harrington and K. J. Reimer Appl. Organomet. Chem., 1997, 11, 797.

18 S. H. Hansen, E. H. Larsen, G. Pritzl and C. Cornett, J. Anal. At. Spectrom., 1992, 7, 629.

19 D. Kuehnelt, W. Goessler and K. J. Irgolic, Appl. Organomet. Chem., 1997, 11, 459.

20 Y. Shibata and M. Morita, Anal. Sci., 1989, 5, 107.

21 P. Thomas and K. Sniatecki, Fresenius' J. Anal. Chem., 1995, 351 , 410

22 C. B'Hymer, K. L. Sutton and J. A. Caruso, J. Anal. At Spectrom., 1998, 13, 855.

23 Z. Mester and P. Fodor, J. Anal. At. Spectrom., 1997, 12, 363.

24 W. Goessler, W. Maher, K. J. Irgolic, D. Kuehnelt, C. Schlagenhaufen and T. Kaise, Fresenius' J. Anal. Chem., 1997, 359, 434.

25 W. Goessler, D. Kuehnelt, C. Schlagenhaufen, Z. Slejkovec and K. J. Irgolic, J. Anal. Atom. Spectrom., 1998, 13, 183. 